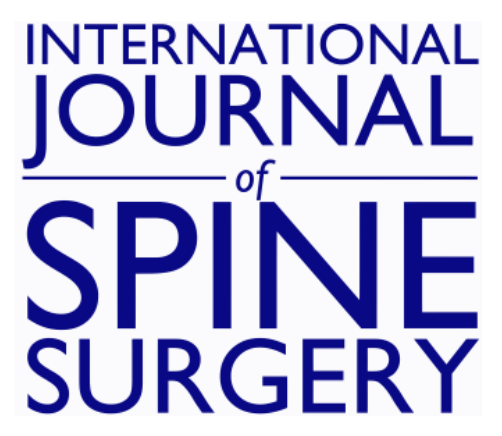

\title{
Morphometric Analysis of Subaxial Cervical Spine Pedicles in a Middle Eastern Population
}

Khalid Alsaleh, Fahad Essbaiheen, Khalifah Aldosari, Bandar Alsubei and Mahammad Alabdulkareeem

Int J Spine Surg 2021, 15 (3) 413-417

doi: https://doi.org/10.14444/8061

http://ijssurgery.com/content/15/3/413

This information is current as of April 26, 2023.

Email Alerts Receive free email-alerts when new articles cite this article. Sign up at: http://ijssurgery.com/alerts 


\title{
Morphometric Analysis of Subaxial Cervical Spine Pedicles in a Middle Eastern Population
}

\author{
KHALID ALSALEH, FRCSC, ${ }^{1}$ FAHAD ESSBAIHEEN, FRCPC, ${ }^{2}$ KHALIFAH ALDOSARI, MBBS, ${ }^{3}$ \\ BANDAR ALSUBEI, MBBS, ${ }^{1}$ MAHAMMAD ALABDULKAREEEM, MBBS ${ }^{2}$ \\ ${ }^{I}$ Department or Orthopedics, College of Medicine, King Saud University, Riyadh, Saudi Arabia ${ }^{2}$ Department of Radiology, College of Medicine, King Saud \\ University, Riyadh, Saudi Arabia ${ }^{3}$ College of Medicine, King Saud University, Riyadh, Saudi Arabia
}

\begin{abstract}
Background: Pedicle screw instrumentation of the posterior cervical spine is the most secure form of fixation available to surgeons. It has not achieved widespread use yet in the Middle East, mostly due to concerns regarding its feasibility in the target population. A detailed morphometric analysis of the lower cervical spine pedicles using computerized tomography (CT) was proposed to address this issue.

Methods: Two hundred and seventy patients were enrolled in the study. CT scans were reviewed by two experienced assessors, and measurements of pedicle width (PW), height $(\mathrm{PH})$, and transverse angle (TA) were recorded for all patients. Interobserver and intraobserver reliability were calculated using the kappa statistic. Sex differences were also recorded and analyzed. The $t$ test was used to assess for any significant differences in measurements due to sex $(P<$ $.05)$.

Results: The mean PW varied from $4.4 \mathrm{~mm}$ in $\mathrm{C} 3$ to $6.1 \mathrm{~mm}$ in $\mathrm{C} 7$. The mean PH was $6.4 \mathrm{~mm}$ in $\mathrm{C} 3$ and $6.8 \mathrm{~mm}$ in C7. Pedicle TA varied from 42 to 51 degrees between the different levels. Sex differences were observed and were statistically significant for PW and PH. Interobserver reliability was high for PW and PH, but was low for TA. Intraobserver reliability was 0.99 for both assessors.

Conclusion: This study provides reliable PW and PH measurements and demonstrates that cervical pedicle screw instrumentation is feasible in our local population. Significant variability exists, however, and each patient must be addressed individually for best results.

Level of Evidence: 3.

Clinical Relevance: This study shows that the morphology of the subaxial cervical pedicle permits instrumentation in a majority of cases of our target population.

Cervical Spine

Keywords: cervical spine, pedicle screw, computed tomography
\end{abstract}

\section{INTRODUCTION}

Posterior instrumentation of the subaxial cervical spine has evolved over the past few decades. Wiring techniques were superseded by lateral mass screws by the end of the 20th century. Cervical pedicle screw instrumentation was first described in 1994 by Abumi et al. ${ }^{1}$ Biomechanically, the cervical pedicle screw is far stronger than any lateral mass screw. ${ }^{2,3}$ Widespread use of this technique, however, has not been achieved. Variability in the cervical anatomy and risks to the neurologic and vascular structures are well documented in the literature. ${ }^{4,5}$

Ethnic variability in cervical pedicle anatomy was established by several previous reports. ${ }^{6-9}$ Cervical pedicle screw instrumentation is rarely used in our region, with reluctance usually attributed to the small size of cervical pedicles in our population. Given the scarcity of published data accurately representing our target population, it is difficult to support this argument. We aim in this study to quantify the cervical pedicle width, height and transverse angulation in our target population and compare it with existing data from other reports.

\section{MATERIALS AND METHODS}

Computerized tomographic (CT) scans of 300 consecutive adult patients (over 18 years of age) undergoing cervical spine imaging for various indications in our institution (located in Riyadh, Saudi Arabia) were included for the purpose of this study. Institutional research ethics board approval was granted before starting the study. Patients with congenital abnormalities, previous surgery, infec- 


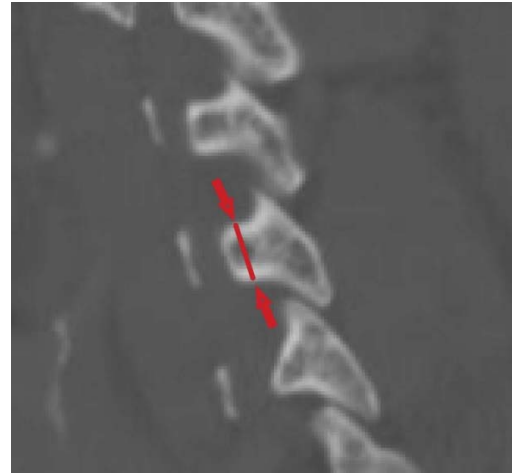

Figure 1. Pedicle height.

tions, neoplastic lesions, or trauma to the cervical spine were excluded. Expatriates and other noncitizens were excluded to allow for a better representation of our target population.

The CT scans were performed on 64-slice multidetector scanners; SOMATOM Definition (Siemens Healthcare; Erlangen, Germany), Discovery 750HD, and Lightspeed VCT (GE Healthcare) using the following parameters: helical acquisition, $120 \mathrm{kVp}, 70-80 \mathrm{mAs}, 512 \times 512 \times 16$ matrix, 0 gantry tilt, and a slice thickness of $0.625 \mathrm{~mm}$. Images were retrieved using the institution picture archiving and communication system (Centricity 4.2, GE Healthcare).

Measurements taken included pedicle width, pedicle height, and pedicle transverse angle from $\mathrm{C} 3$ to $\mathrm{C} 7$ unilaterally. The pedicle width was defined as the largest medial to lateral measurement of the pedicle isthmus taken in the axial view, including the cortex. The pedicle height was defined as the largest superior to inferior measurement of the pedicle isthmus taken in the sagittal view, including the cortex. The pedicle transverse angle was defined as the angle between the mid-sagittal axis (line from the midpoint of the anterior cortex to the tip of the

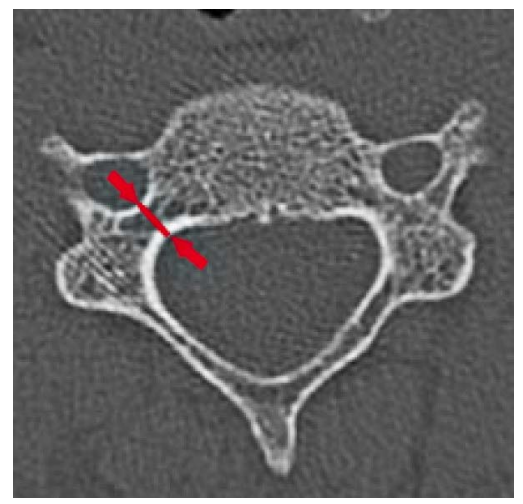

Figure 2. Pedicle width.

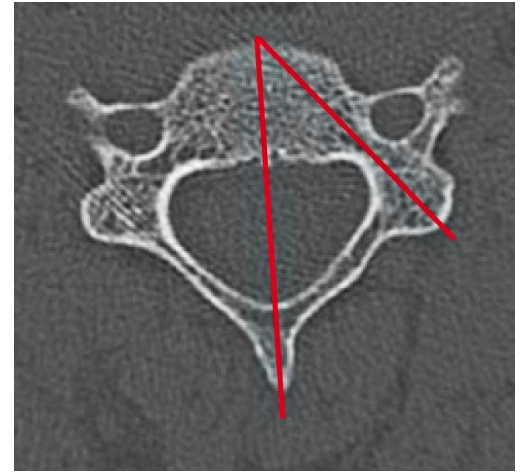

Figure 3. Pedicle transverse angle.

spinous process) and the pedicle axis on the axial view (Figures 1-3). The measurements were taken independently by a consultant orthopedic surgeon (KA) and a consultant radiologist (FE) using the previously agreed upon criteria for measurement. The data were then analyzed for interrater reliability using the kappa statistic. A random sample of 20 patients had repeat measurements done 1 month later for measurement of intrarater reliability, again using the kappa statistic. The mean and standard deviation were calculated for all measurements. The $t$ test was used to assess for any significant difference in pedicle measurements due to sex $(P<.05)$. Statistical analysis was performed using SPSS software (version 24, IBM Corp., Armonk, New York).

\section{RESULTS}

Three hundred consecutive patients who underwent cervical spine CT were included into the initial sample. After application of exclusion criteria, 270 patients made the final sample for analysis. A total of 1350 pedicles were measured to obtain 4050 measurements. The sample was composed of 154 males and 116 females. The average age was 40 years old (range, 18-92). The pedicle measurements and interobserver reliability are shown in Tables 1-3. Intraobserver reliability was 0.99 for both assessors. Sex differences were

Table 1. Pedicle width measurements.

\begin{tabular}{lcccccc}
\hline $\begin{array}{l}\text { Pedicle } \\
\text { Width }\end{array}$ & Orthopedic & Radiology & Kappa & Overall & Range & SD \\
\hline C3 & 4.5 & 4.4 & 0.953 & 4.4 & 5.2 & 0.8 \\
C4 & 4.5 & 4.4 & 0.968 & 4.5 & 7.3 & 0.9 \\
C5 & 5 & 4.8 & 0.921 & 4.9 & 5.6 & 0.8 \\
C6 & 5.2 & 5 & 0.941 & 5.1 & 5.2 & 0.9 \\
C7 & 6.3 & 6 & 0.954 & 6.1 & 8.8 & 1
\end{tabular}

Abbreviations: SD, standard deviation. 
Table 2. Pedicle height measurement.

\begin{tabular}{lcccccc}
\hline $\begin{array}{l}\text { Pedicle } \\
\text { Height }\end{array}$ & Orthopedic & Radiology & Kappa & Overall & Range & SD \\
\hline C3 & 6.5 & 6.3 & 0.666 & 6.4 & 70.8 & 3.1 \\
C4 & 6.4 & 6.7 & 0.513 & 6.6 & 5.5 & 1 \\
C5 & 6.3 & 6.3 & 0.722 & 6.3 & 6.1 & 1 \\
C6 & 6.4 & 6.3 & 0.93 & 6.3 & 6.4 & 1 \\
C7 & 6.3 & 6.7 & 0.911 & 6.8 & 6.6 & 1 \\
\hline
\end{tabular}

Abbreviations: SD, standard deviation.

observed for all three measurements (Figures 4$6)$.

\section{DISCUSSION}

The first report on cervical pedicle measurements was published in 1991 by Punjabi et al. ${ }^{10}$ His study was done on cadavers, and pedicle measurements were done in addition to other anatomical landmarks of the cervical spine. The first CT-based morphometric analysis of the subaxial spine was reported in 1997 by Ebraheim et al. ${ }^{11}$ In the same year, Karaikovic et al $^{12}$ published a similar study, but validated the CT measurements by manual measurement of cadaver specimens and found that the measurements correlated well. Several other reports came about afterwards that showed that sex- and ethnic-based variations existed. ${ }^{6,8,9,13-21}$ Chazono, ${ }^{22}$ an author of one of the aforementioned reports, reviewed some of these publications and found that the reported ethnic differences were within $10 \%-15 \%$ of each other.

Al-Saeed et $\mathrm{al}^{20}$ reported on cervical spine pedicle measurements from Kuwait. This study, while well planned and conducted, had a smaller sample size than our study. Given that our target population, supposedly, is of the same ethnicity, we found significant variability between our measurements and theirs, where their data were $0.5-0.7 \mathrm{~mm}$ larger in both pedicle height and width. That could be because their included patients, although "citizen of an Arab country", were probably not natives of the

Table 3. Pedicle transverse angle measurement.

\begin{tabular}{lcccccc}
\hline $\begin{array}{l}\text { Pedicle } \\
\text { Angle }\end{array}$ & Orthopedic & Radiology & Kappa & Overall & Range & SD \\
\hline C3 & 53.1 & 44.1 & 0.04 & 48.6 & 37 & 6.9 \\
C4 & 54.2 & 46.7 & 0.13 & 50.4 & 34.2 & 6.2 \\
C5 & 54 & 47.3 & 0.322 & 50.6 & 66.7 & 6.8 \\
C6 & 51.5 & 44.2 & 0.208 & 47.9 & 38.2 & 7.1 \\
C7 & 47.8 & 35.5 & 0.09 & 41.6 & 40.4 & 9.2
\end{tabular}

Abbreviations: SD, standard deviation.

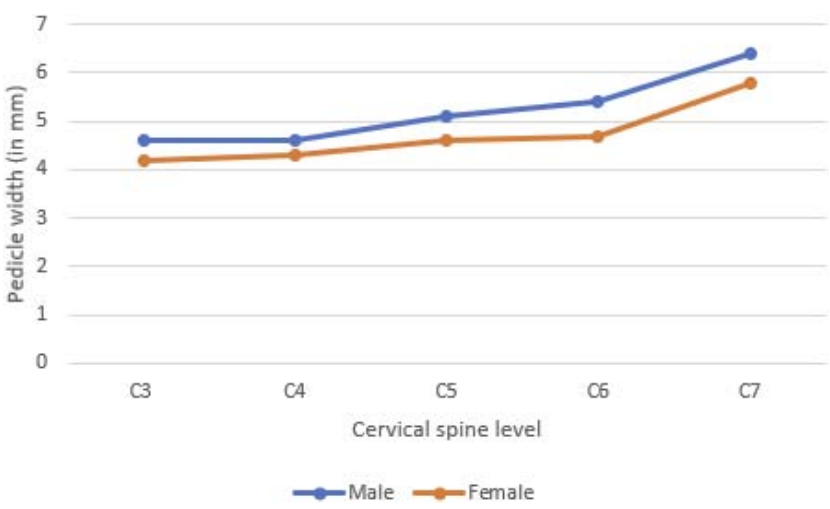

Figure 4. Pedicle width measurement by $\operatorname{sex}(P<.05$ for all measurements).

country, as a large expatriate Arab population populates their country. Our study was limited to Saudi citizens and, as such, is probably more representative of an Arab/ Middle Eastern population.

The measurements presented in this study are similar to other Asian countries. ${ }^{8,9,16,19,23-25}$ Taking into account the thickness of the cortex, 0.5 $\mathrm{mm}$ for most levels, cannulation and instrumentation of $\mathrm{C} 5, \mathrm{C} 6$, and $\mathrm{C} 7$ with a $3.5-\mathrm{mm}$ screw is certainly feasible in our population, but more so in males than in females. The transverse angle decreasing as we go into the lower levels also helps the starting point be within reach within the operative field.

This study is the largest CT-based morphometric analysis of human cervical spine pedicles done to date; however, this study may be limited as its measurements were limited to the three mentioned above, while other reports had more extensive data points collected. The authors believe that, from a clinical application perspective, these measurements are all that is needed to understand pedicle morphology and plan surgical treatment.

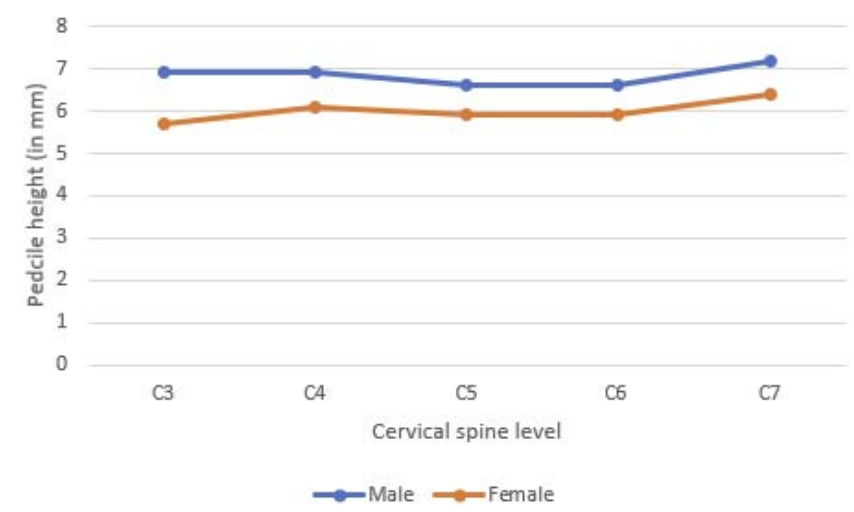

Figure 5. Pedicle height measurement by $\operatorname{sex}(P<.05$ for all measurements). 


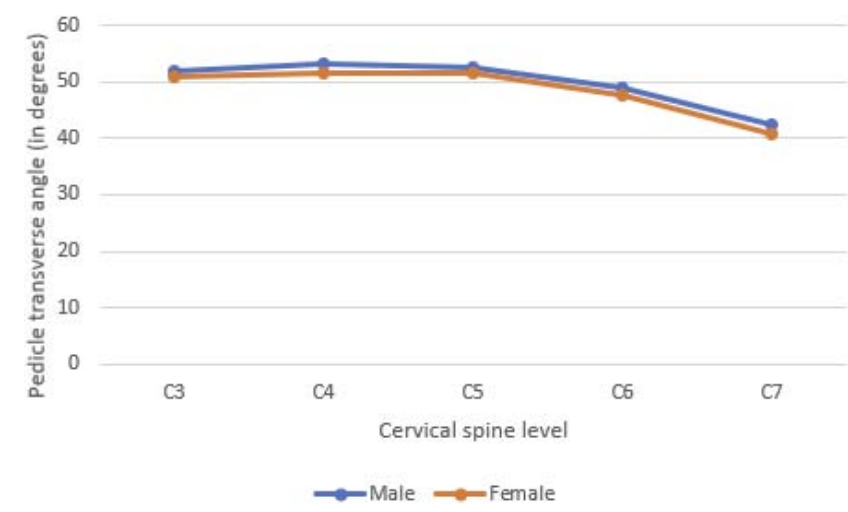

Figure 6. Pedicle transverse angle by sex $(P<.05$ for $\mathrm{C} 3-\mathrm{C} 5$ only).

\section{CONCLUSION}

Cervical spine pedicle instrumentation is a useful tool in the armamentarium of spine surgeons. Although difficult in some cases, this current study shows that the morphology of the pedicle permits it in most levels and most cases. Nevertheless, a detailed review of each patient's CT results before surgery should be performed as significant anatomical variability exists, and the risk of neurovascular complication cannot be underestimated with this technique. More widespread availability of intraoperative CT imaging and navigation could help this technique gain more proponents in our region.

\section{REFERENCES}

1. Abumi K, Itoh H, Taneichi H, Kaneda K. Transpedicular screw fixation for traumatic lesions of the middle and lower cervical spine: description of the techniques and preliminary report. J Spinal Disord. 1994;7(1):19-28.

2. Jones EL, Heller JG, Silcox DH, Hutton WC. Cervical pedicle screws versus lateral mass screws. Anatomic feasibility and biomechanical comparison. Spine (Phila Pa 1976). 1997;22(9):977-982.

3. Johnston TL, Karaikovic EE, Lautenschlager EP, Marcu D. Cervical pedicle screws vs. lateral mass screws: uniplanar fatigue analysis and residual pullout strengths. Spine $J$. 2006;6(6):667-672.

4. Kotil K, Akçetin MA, Savas Y. Neurovascular complications of cervical pedicle screw fixation. J Clin Neurosci. 2012;19(4):546-551.

5. Nakashima H, Yukawa Y, Imagama S, et al. Complications of cervical pedicle screw fixation for nontraumatic lesions: a multicenter study of 84 patients. $J$ Neurosurg Spine. 2012;16(3):238-247.

6. Bozbuga M, Ozturk A, Ari Z, Sahinoglu K, Bayraktar B, Cecen A. Morphometric evaluation of subaxial cervical vertebrae for surgical application of transpedicular screw fixation. Spine (Phila Pa 1976). 2004;29(17):1876-1880.
7. Onibokun A, Khoo LT, Bistazzoni S, Chen NF, Sassi M. Anatomical considerations for cervical pedicle screw insertion: the use of multiplanar computerized tomography measurements in 122 consecutive clinical cases. Spine J. 2009;9(9):729-734.

8. Munusamy T, Thien A, Anthony MG, Bakthavachalam R, Dinesh SK. Computed tomographic morphometric analysis of cervical pedicles in a multi-ethnic Asian population and relevance to subaxial cervical pedicle screw fixation. Eur Spine J. 2015;24(1):120-126.

9. Farooque K, Yadav R, Chowdhury B, Gamanagatti S, Kumar A, Meena PK. Computerized tomography-based morphometric analysis of subaxial cervical spine pedicle in asymptomatic Indian population. Int J Spine Surg. 2018;12(2):112-120.

10. Panjabi MM, Duranceau J, Goel V, Oxland T, Takata K. Cervical human vertebrae. Quantitative three-dimensional anatomy of the middle and lower regions. Spine (Phila Pa 1976). 1991;16(8):861-869.

11. Ebraheim $\mathrm{NA}, \mathrm{Xu} \mathrm{R}, \mathrm{Knight} \mathrm{T}$, Yeasting RA. Morphometric evaluation of lower cervical pedicle and its projection. Spine (Phila Pa 1976). 1997;22(1):1-6.

12. Karaikovic EE, Daubs MD, Madsen RW, Gaines RW Jr. Morphologic characteristics of human cervical pedicles. Spine (Phila Pa 1976). 1997;22(5):493-500.

13. Rezcallah AT, Xu R, Ebraheim NA, Jackson T. Axial computed tomography of the pedicle in the lower cervical spine. Am J Orthop (Belle Mead NJ). 2001;30(1):59-61.

14. Sakamoto T, Neo M, Nakamura T. Transpedicular screw placement evaluated by axial computed tomography of the cervical pedicle. Spine (Phila Pa 1976). 2004;29(22):25102514; discussion 2515.

15. Yusof MI, Ming LK, Abdullah MS. Computed tomographic measurement of cervical pedicles for transpedicular fixation in a Malay population. J Orthop Surg (Hong Kong). 2007;15(2):187-190.

16. Ruofu Z, Huilin Y, Xiaoyun H, et al. CT evaluation of cervical pedicle in a Chinese population for surgical application of transpedicular screw placement. Surg Radiol Anat. 2008;30(5):389-396.

17. Banerjee PS, Roychoudhury A, Karmakar SK. Morphometric analysis of the cervical spine of Indian population by using computerized tomography. Journal of Medical \& Allied Sciences. 2012;2(2):66-76.

18. Chanplakorn P, Kraiwattanapong C, Aroonjarattham $\mathrm{K}$, et al. Morphometric evaluation of subaxial cervical spine using multi-detector computerized tomography (MD-CT) scan: the consideration for cervical pedicle screws fixation. $B M C$ Musculoskelet Disord. 2014;15:125. doi:10.1186/1471-2474-15125

19. Wasinpongwanich K, Paholpak P, Tuamsuk P, et al. Morphological study of subaxial cervical pedicles by using three-dimensional computed tomography reconstruction image. Neurol Med Chir (Tokyo). 2014;54(9):736-745.

20. Al-Saeed O, Marwan Y, Kombar OR, Samir A, Sheikh M. The feasibility of transpedicular screw fixation of the subaxial cervical spine in the Arab population: a computed tomography-based morphometric study. J Orthop Traumatol. 2016;17(3):231-238. 
21. Chazono M, Soshi S, Inoue $\mathrm{T}$, Kida $\mathrm{Y}$, Ushiku $\mathrm{C}$. Anatomical considerations for cervical pedicle screw insertion: the use of multiplanar computerized tomography reconstruction measurements. J Neurosurg Spine. 2006;4(6):472-477.

22. Chazono M, Tanaka T, Kumagae Y, Sai T, Marumo K. Ethnic differences in pedicle and bony spinal canal dimensions calculated from computed tomography of the cervical spine: a review of the English-language literature. Eur Spine $J$. 2012;21(8):1451-1458.

23. Tan SH, Teo EC, Chua HC. Quantitative threedimensional anatomy of cervical, thoracic and lumbar vertebrae of Chinese Singaporeans. Eur Spine $J$. 2004;13(2):137-146.

24. Rao RD, Marawar SV, Stemper BD, Yoganandan N, Shender BS. Computerized tomographic morphometric analysis of subaxial cervical spine pedicles in young asymptomatic volunteers. J Bone Joint Surg Am. 2008;90(9):1914-1921.

25. Saluja S, Patil S, Vasudeva N. Morphometric analysis of sub-axial cervical vertebrae and its surgical implications. J Clin Diagn Res. 2015;9(11):Ac01-04.

Disclosures and COI: The authors have nothing to disclose.

Corresponding Author: Khalid Alsaleh, FRCSC, Department or Orthopedics, College of Medicine, King Saud University Medical City, King Saud University, Riyadh 12372, Saudi Arabia. Phone: +96 (611) 806-6430; Email: khalsaleh@ksu.edu.sa.

Published 1 June 2021

This manuscript is generously published free of charge by ISASS, the International Society for the Advancement of Spine Surgery. Copyright (C) 2021 ISASS. To see more or order reprints or permissions, see http://ijssurgery.com. 